\title{
O Processo de Reminiscências : um Meio de Integrar Gerações; uma Alternativa de Promover Saúde
}

\section{Reminiscence Process: a Means of Intergenerational Interaction; an Alternative Way of Health Promotion}

\author{
Elza Maria de Souza ${ }^{1}$
}

\section{Resumo}

\begin{abstract}
O Brasil está evidenciando um rápido aumento da população idosa, porém o número de jovens na população ainda continua elevado. Esses dois grupos etários são, em geral, considerados improdutivos e consumidores de recursos. No entanto, jovens e idosos podem dar uma imensa contribuição à sociedade por meio de atividades de integração intergeracional, pouco exploradas no país. Em 1998 foi iniciado um projeto de integração entre gerações na Cidade de Ceilândia, Distrito Federal. As atividades tinham o propósito de promover o bem estar dos idosos, crianças e adolescentes, usando-se o processo de reminiscências como estratégia de integração. A finalidade deste estudo é avaliar o projeto de acordo com a opinião dos participantes e enfatizar a contribuição de jovens e idosos na promoção do bem estar individual e coletivo. De novembro de 1999 a abril de 2000 foi conduzida uma pesquisa qualitativa usando-se a técnica dos grupos focais. Seguindo-se um roteiro foram entrevistados, treze grupos de estudantes de 8 a 13 anos de idade, 3 grupos de idosos de 60 anos ou mais e um grupo de professoras, com o objetivo de avaliar atividades conjuntas entre jovens e idosos. Os resultados sugerem mudança de atitude dos alunos e professores em relação aos idosos e à velhice. Os idosos relataram melhora no estado de saúde. Para todos os grupos, os achados sugerem aprimoramento da convivência entre gerações. Os achados parecem indicar que atividades de integração entre gerações, usando-se o processo de reminiscências contribuem para fortalecer normas de solidariedade e a confiança mútua entre gerações, podendo ser uma alternativa de investimento no bem estar dos participantes. No entanto, estudos adicionais serão necessários para comprovar esses achados.
\end{abstract}

Palavras Chave: Promoção da saúde, Integração entre gerações, Reminiscências

\begin{abstract}
Brazil is now witnessing a rapid ageing of the population process at the same time that the proportion of young people in the population is still high. These age groups are usually considered unproductive and consumers of resources. However, both, young and elderly people can give an enormous contribution to society through intergenerational activities, still little explored in the country. In 1998 an intergenerational project was initiated in Ceilândia, situated in the Federal District of Brasília, as an extension of a pilot programme previously initiated in the city of Taguatinga, in the same region. The project aimed to promote the well being of elders, children and adolescents, using reminiscence processes as a means of interaction. The purpose of this study is to evaluate the project according to the participants' point of view and to enhance the contribution they could give for the individual and the community well-being.
\end{abstract}

\footnotetext{
Médica e Pesquisadora da Secretaria de Estado de Saúde do Distrito Federal. Especialização em Geriatria e Gerontologia, Southampton University - Inglaterra (1989-1991).Mestrado em Ciências da Saúde, Universidade de Brasília, Brasília DF (19951997).Doutoranda em Promoção da Saúde - London School of Hygiene and Tropical Medicine, Londres- Inglaterra e-mail: elza.desouza@1shtm.ac.uk
} 
From November 1999 to April 2000 a qualitative research project using focus groups technique was conducted. Following a discussion guide, 13 groups of students, ranging in age from 8 to 13 years old, 3 groups of elders of 60 years old or over, and one group of teachers were interviewed so as to collect data related to the intergenerational interaction programme developed in Ceilandia, Federal District, Brazil. The main findings suggested a change in attitude of students and teachers toward old age and elderly people. Participating elders reported improvement in their health condition. For all participants the findings suggested a better understanding between generations. It seems that the reminiscence intergenerational activities contribute to building mutual trust and solidarity between generations. These results seem to indicate that this is an alternative way to invest in health and in the well-being of young and elderly people. However, further work is needed to support these findings.

Key Words: Health promotion, Intergenerational interaction, Reminiscence

\section{Introdução}

O Brasil tem apresentado um rápido aumento na população idosa, porém a proporção de jovens na população ainda é elevada. Esse fato torna urgente a busca de estratégia de promoção de saúde para esses dois segmentos sociais.

Jovens e idosos têm sido, via de regra, considerados grupos dependentes e improdutivos. Enquanto a velhice tem sido associada principalmente a doenças crônicas e incapacidade, a adolescência tem sido associada, em geral, ao uso de drogas, violência, gravidez precoce e AIDS. Embora de extrema importância para a saúde pública, essa visão unilateral pode perpetuar preconceitos e estereótipos, prejudicando a elaboração de políticas públicas voltadas para esses dois grupos etários. No entanto, jovens e idosos apresentam um potencial para o desenvolvimento de ações conjuntas que podem contribuir para o bemestar individual e coletivo, o qual não tem recebido a devida atenção em nosso país.

\section{Integração entre gerações uma atividade em ascensão}

As últimas duas décadas têm testemunhado o interesse crescente em programas de integração ente gerações (KUEHNE; COLLIN, 1997; KERRIGAN; STEVENSON, 1997), principalmente em países europeus e norte-americanos (HIRSHORN; PIERING, 1999; GIBSON, 1998). Esse interesse deriva da percepção de várias categorias profissionais, incluindo terapeutas, assistentes sociais e educadores, do potencial de conhecimento e experiências que podem ser compartilhadas em interações entre pessoas de diferentes idades. Esse movimento "intergeracional" extrapola o interesse em combater a segregação etária e o preconceito em relação à velhice, para atingir objetivos mais amplos que têm, entre outras finalidades, estimular a transmissão cultural (HENKIN, 1997) e minimizar problemas sociais, tais como violência juvenil, a evasão escolar e o uso de drogas (WARD, 1997). Devido a seu alcance, esse programa foi, recentemente, incluído em programas de promoção da saúde (SOUZA, 2001; ROBINSON, 2000; SOUZA, 1999). Embora o interesse nessa área esteja crescendo, poucos programas têm sido devidamente avaliados por metodologia científica reconhecida, o que torna difícil a comprovação da efetividade desses programas e a disseminação de seus resultados.

\section{Uma experiência no Distrito Federal}

De acordo com a definição proposta pela Carta de Ottawa (WORLD HEALTH ORGANIZATION, 1986), a promoção da saúde é o processo que confere às populações os meios de assegurar o controle e o aprimoramento de sua saúde. Essa concepção de promoção de saúde tem-se tornado uma força vital no movimento de saúde publica, pois nele a saúde é concebida também como um fenômeno social que, para ser atingido, requer integração intersetorial, alianças multidisciplinares e participação comunitária ativa.

Considerando os preceitos da Carta de Ottawa, o Programa de Atenção Integral à Saúde do Idoso 
da Secretaria de Estado de Saúde, em colaboração com escolas da rede pública de ensino do Distrito Federal, iniciou, em 1994, um projeto no qual é aproveitado o potencial de jovens e idosos para a promoção da saúde dos participantes (SOUZA, 2001, 1999,1997). Dessa forma, foi o precursor em implantar ações de integração entre gerações com o "Projeto Reminiscências: integrando gerações." Esse projeto, foi iniciado em escolas da Cidade de Taguatinga, DF (SOUZA, 2003). Quatro anos depois, as atividades de integração entre gerações foram implantadas na Cidade de Ceilândia, em uma escola de ensino fundamental, a Escola Classe 15. As atividades destinavam-se a estimular os idosos da comunidade, usuários do Centro de Saúde 4, situado próximo à escola, a compartilhar suas histórias de vida com os alunos. Essas atividades foram iniciadas com o propósito de aprimorar e preservar valores culturais, reduzir o poder de preconceitos e estereótipos entre gerações, prevenir o isolamento social e, dessa forma, aprimorar o sentimento de bemestar dos participantes. Aproximadamente 800 alunos de 8 a 13 anos de idade da primeira à quarta séries, 35 idosos da comunidade e oito professoras tomaram parte no projeto no período de 1998 a 2000.

Os encontros eram realizados na sala de reminiscências, local em que eram expostos objetos antigos doados pelos próprios idosos e trabalhos desenvolvidos nas oficinas de reminiscências. Cada encontro ou sessão tinha a duração média de uma hora e acontecia com uma periodicidade de 15 a 20 dias com cada classe de alunos. Os encontros eram facilitados pelos professores, os quais receberam um treinamento sobre as técnicas e aspectos éticos para a prática de reminiscências ministrado pela coordenadora do projeto. Para evocar a memória, diferentes estímulos eram usados tais como: objetos antigos, cantigas de infância, fotos e outros. Os relatos dos idosos eram registrados e ilustrados pelos alunos.

O processo de reminiscências foi adotado como estratégia de integração, considerando-se a importância da prática para os idosos e o valor cultural para a comunidade (COLEMAN, 1986;
BORNAT, 1994). A operacionalização pormenorizada dessas ações está descrita em outra publicação (SOUZA, 1999). O propósito desse estudo é avaliar as atividades do Projeto Reminiscências: integrar gerações sob o ponto de vista dos participantes, bem como realçar a importância da integração entre gerações por meio do processo de reminiscências na promoção da saúde.

\section{Metodologia}

Para avaliação do projeto acima descrito foi desenvolvido um estudo qualitativo, empregando-se a técnica dos grupos focais, no período de novembro de 1999 a maio de 2000. Um total aproximado de 100 jovens, 35 idosos e oito professoras foram distribuídos em grupos formados, em média, por 8 componentes cada. Foram conduzidos 13 grupos de alunos de 8 a 13 anos de idade da Escola Classe 15 de Ceilândia, estratificados por idade e sexo, 3 grupos de idosos com idade igual ou superior a 60 anos de idade e um grupo de professoras, conforme mostra a figura 1. Para a inclusão no estudo, os integrantes do projeto deveriam estar participando das atividades por um período mínimo de um ano. Utilizando-se um roteiro de perguntas semi estruturadas (quadro 1), os grupos focais foram conduzidos e as discussões gravadas em fitas cassete por duas facilitadoras, estudantes universitárias, que não tinham participação nas atividades do projeto, devidamente treinadas na metodologia utilizada, pela coordenadora da pesquisa. As fitas foram transcritas verbatim e feita a análise temática .

Quadro 1. Roteiro para discussão dos grupos focais utilizado na avaliação do Projeto reminiscências integrando gerações

\begin{tabular}{|l|}
\hline 1) O que vocês aprenderam com o Projeto Reminiscências? \\
\hline 2) Do que vocês mais gostaram no Projeto Reminiscências? \\
\hline 4) Do que vocês não gostaram no Projeto Reminiscências? \\
\hline 5) A quem vocês indicariam as atividades do Projeto Reminiscências? \\
\hline 6) Como a participação no Projeto modificou a sua opinião sobre a velhice? \\
\hline 7) Como a participação no projeto modificou a sua relação com a família? \\
\hline 8) De que maneira o projeto influenciou a sua saúde? \\
\hline
\end{tabular}




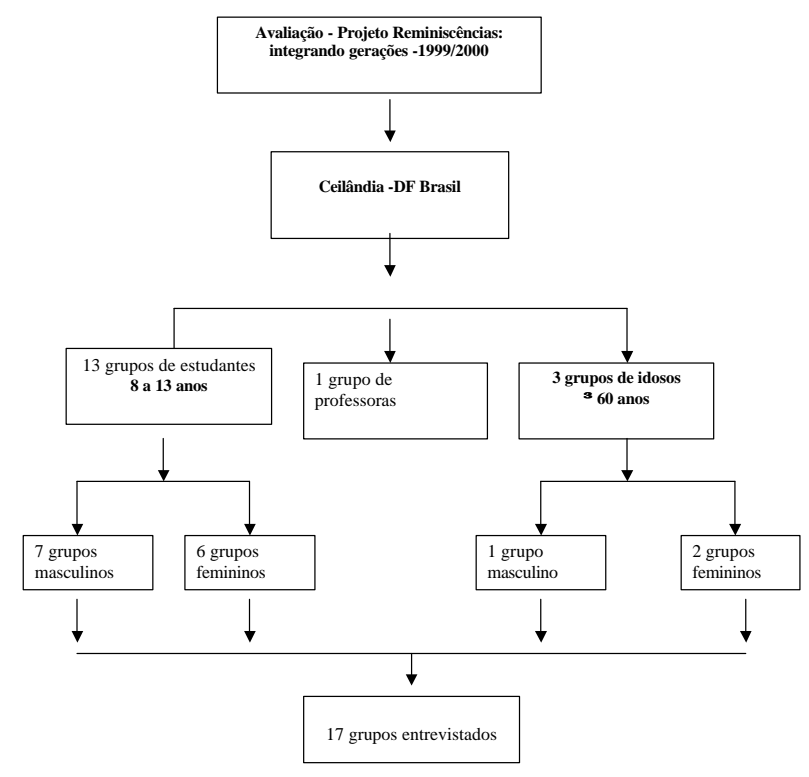

Figura 1. Representação esquemática da distribuição dos grupos focais por idade e sexo .

\section{Resultados e Discussão}

Os resultados descritos mostram as impressões que predominaram entre os grupos.

\section{Avaliação sob o ponto de vista dos alunos}

A maioria dos grupos referiu como aprendizado o conhecimento e a valorização do passado, o que os levam a gostar dos idosos, a valorizá-los e não discriminá-los. Chama atenção o fato de os alunos referirem que o aprendizado é mútuo, bem como o respeito, fato relatado por todos os grupos e resumido nos seguintes comentários:

Eu achei bom porque a gente aprende com eles e eles aprendem com a gente. Eles ajudam a gente a melhorar esse mundo que está aí.

Foi bom porque a gente aprendeu a respeitar eles e eles a respeitar a gente.

Quanto àquilo de que eles mais gostaram no projeto, salientaram a amizade com os mais velhos, as informações sobre os costumes de outrora e o aprendizado mútuo.

No que se refere à indicação, a maioria dos grupos indicaria principalmente para os próprios jovens, mostrando o valor que tem para a juventude essa convivência. Um grupo referiu a importância de iniciar as atividades com jovens infratores privados de liberdade, sugerindo que as atividades de reminiscências nas escolas poderiam ser um meio de prevenir a violência juvenil.

É possível perceber que as ações do projeto recebem a aprovação dos jovens, no entanto existem pontos negativos que merecem uma intervenção para o melhor direcionamento das atividades. Conforme depoimentos, existem alunos que ainda têm preconceitos e alguns dos que estão participando não estão interessados e atrapalham os demais. Esse fato foi referido por alguns grupos como "um desrespeito". Essa observação é particularmente interessante porque a literatura recomenda que os grupos de trabalho sejam formados no máximo por dez componentes (GIBSON, 1998; SOUZA, 1999). Nesse projeto, os professores, por impossibilidade de dividir as turmas, trabalharam com as classes inteiras, sendo dessa forma, difícil manter o interesse de todos. Os alunos queixaram-se também de que o número de idosos era pequeno e a duração dos sessões, em média de 60 minutos, era muito curta, não sendo possível aprofundar as questões. Referiram ainda que a periodicidade quinzenal (e às vezes mensal) dos encontros era muito longa, sugerindo que fossem realizadas pelo menos

Em relação à opinião sobre a velhice, todos os grupos referiram mudanças de atitudes. Antes da participação nas atividades a maioria tinha muito preconceito em relação à velhice, ilustrada nos seguintes comentários:

Eu achava que a velhice era uma chatice.

Eu pensava que velho era só velho e não sabia de nada.

Antes eu pensava: pra que velho existe? Agora eu me arrependo e mudei tudo.

Sem esse projeto, até hoje eu não estaria respeitando os velhos. É muito errado desprezá-los. 
Foi feita também alusão à velhice como sinônimo de doença e incapacidade. Enquanto outros associavamna à monotonia e à solidão, idéias essas descritas em outros estudos (STONES; STONES, 1998; SEYMOUR, 1994; TUKMAN; LORGE, 1953, 1952). Esses achados contrariam os resultados encontrados por Neri (1991), a qual verificou que as atitudes dos jovens em relação à velhice não eram tão negativas como se supunham, ao contrário dos achados no presente estudo. Tal divergência pode estar relacionada à diferença metodológica e ao fato de a referida autora ter trabalhado com uma amostra de voluntários, o que pode sugerir que aqueles que aceitaram entrar no estudo já tivessem uma atitude mais positiva para com os idosos. Os estudos de atitude em relação à velhice tem mostrado resultados bastante controversos, variando de atitudes positivas, negativas e indiferentes (STONES; STONES, 1998; NEWMAN et al., 1997;. HICKS et al., 1976; BRUBAKER; POWERS, 1976).

Finalmente houve interesse em saber se o contato com os idosos teria modificado a relação familiar. Os resultados são surpreendentes, indicando que os jovens passaram a compreender melhor não só os avós, mas também os pais conforme ilustra os comentários seguintes:

A gente respondia os idosos. Depois que eu falei isso que estou aprendendo para um colega ele parou de responder a avó dele. Eu falei que o que os idosos estão ensinando para a gente é uma coisa boa e a gente está passando alguma coisa para eles e eles para a gente. A gente aprende muita coisa que não sabia e passa para outras. Não só parei de responder meus avós como meus pais.

Até uma dessas músicas de antigamente, que aprendemos, eu ensinei para o meu irmão e comecei a brincar com ele. As pessoas acham que, quem canta essas músicas, é careta. A gente aprendeu com eles que a vida não é só brincadeira, tem hora para tudo: para ajudar os pais, estudar [...].

Depois que a gente escuta todas as histórias deles e sabe que os nossos avós passaram também por tudo aquilo, por aquele sofrimento a gente fica mais apegado aos nosso avós e aos idosos.
Parei de xingar, responder. É muito importante respeitar os idosos porque não é a toa que ensinam as coisas. É porque já passaram por isso. Eu aprendi que a vida não é só xingamento e sair pra rua. Antes eu não falava muito com minha avó. Agora, eu saiu com ela. Faço coisas que não fazia antes.

É super legal viver, trabalhar e fazer muitas coisas com eles. Além de ajudá-los, eles nos ajudam a aprender mais coisas. Muito legal, por que o contato que eu estou tendo com eles de repente eu posso chegar em casa e ter com a minha avó e vice-versa. Então, é como se eles fossem meus avós.

Antigamente eu não "dava bola" para a minha avó. Agora eu dou benção e falo com ela. Depois que eles falaram como a vida deles era bem mais difícil que a nossa, a gente resolveu trabalhar pelo menos um pouquinho. Tem pessoas que têm até vergonha de andar com velhos e de que os avós o deixem no colégio. Eu não dava importância para o que a minha avó falava e só queria saber do hoje, mas agora não. Antes eu falava que a cara da minha avó era toda enrugada e agora eu vou para a casa dela, passo um tempo conversando com ela. Ela me conta um monte de coisa e a gente é superamigas.

Meus primos pequenos ficavam chutando os idosos aí eu achava errado e explicava para os meus primos, porque o Reminiscências explicou para nós . O meu primo agora está carinhoso com a minha tia.

\section{Avaliação dos idosos}

A opinião dos idosos sugere também o aprendizado mútuo e a mudança de atitude em relação aos jovens, como pode ser visto nas seguintes afirmações:

Eu achei muito decente esse projeto, a gente aprende com eles e eles aprendem com a gente.

Agora a gente sabe que nem todo jovem é rebelde e eles sabem que nem todo velho é implicante.

Todos os grupos referiram percepção mais positiva do estado de saúde o que está resumido nos comentários seguintes: 
Eu achei importante porque faz muito bem para a nossa saúde.

Para mim também foi a cura pros meus esquecimentos, eu não estava sabendo nem escrever mais o meu nome, aí depois que eu entrei aqui eu estou relembrando tudo, poesia, moda, música que era do meu tempo.

Isso é bom porque a gente fica em casa triste, chega aqui todo mundo fica alegre e a gente esquece os problemas todos. Isso aqui parece que é vida para gente.

Me senti mais viva, antes eu ficava doente, até para falar era muito difícil que eu sou um pouco surda e eu era também mais calada. Depois que eu comecei aqui, desenvolvi um pouco até na fala.

No tempo que eu ficava só dentro de casa era uma vida perturbada, eu pensava que ia morrer aleijada.

Em relação a modificações na relação familiar, os idosos perceberam maior valorização pelos familiares, situação essa caracterizada nas seguintes afirmações:

Como se diz, a agenda está preenchida, quando eu chego em casa de noite tem visitas, quando não são as netas são as filhas então eu percebo que elas se preocupam mais comigo.

Além de fazer bem para a saúde da gente, a gente conhece outras pessoas.

Estudos prévios têm mostrado que a maior coesão social tem efeitos positivos na saúde (KAWACHI, 1999; STANSFELD, 1999; WILKINSON, 1996) e que, níveis crescentes de participação reduzem a exclusão social, aprimorando o bem estar comunitário (BAUM, 2000). $\mathrm{O}$ presente estudo confirma esses dados.

Quanto aos aspectos negativos do projeto, alguns são compartilhados com a opinião dos jovens, como a duração dos encontros, o longo intervalo entre uma e outra sessão e o número reduzido de idosos. Eles referiram também insatisfação com espaço físico pequeno para as atividades e o ritmo lento da disseminação das atividades

\section{Opinião das professoras}

De acordo a avaliação das professoras, o projeto trouxe a oportunidade de aproximação com os alunos, com os próprios avós e com a comunidade, além de trazer à reflexão aspectos positivos da velhice antes ignorados.

Aprendemos muito. As experiências que nos foram passadas fizeram com que nós refletíssemos mais sobre os nossos pais e os nossos avós.

É uma forma da gente conhecer mais a comunidade que a gente trabalha.

Elas sugeriram também mudança na concepção da velhice, antes vista sob uma perspectiva mais negativa conforme mostra os seguintes depoimentos:

Muitas vezes a gente pensa que vai chegar à Terceira Idade e vai ser aquela monotonia. No entanto, eles passam pra gente outros valores, que na velhice existem outros gostos pelas coisas e isso me fez pensar que na minha velhice eu também quero participar.

Acho que comecei a observar mais porque com a correria do dia a dia a gente não observa as pessoas, não quer saber da vida de ninguém quanto mais de um idoso. Para a gente antigamente era nada.

Para os professores, as atividades de reminiscências também promoveram maior integração e aprendizado mútuo.

Eu acho que o projeto devia continuar. Foi uma riqueza muito grande. Aquela sala com aqueles objetos trouxeram todo um passado que as crianças tiveram oportunidade de vivenciar.

Eu aprendi a dar valor à pequenas coisas. Descobri que o prazer de contar histórias não é só pra mim que estou ouvido. É mais prazeroso pra eles, sabendo que estão passando suas experiência pra alguém.

Em relação à convivência familiar, mesmo para as professoras, o projeto trouxe muitos benefícios presentes nos comentários seguintes: 
Percebi que muitas vezes minha mãe não contava "causos" para os meus filhos. Confesso que passei a observar mais e a trabalhar isso com os meus filhos.

Eu, lá em casa melhorei cem por cento. Agora é uma troca porque antes eu só discutia com meu pai e minha mãe, devido às divergências de jovens com pessoas mais experientes. Eu aprendi a ouvir mais a conversar e a ter mais paciência que eu não tinha.

\section{Limitações ao desenvolvimento das atividades}

A dificuldade maior na manutenção das atividades tem sido as mudanças na direção das escolas, sempre dependentes de ideologias político-partidárias e a alta rotatividade dos professores. A instabilidade política tem sido um dos fatores de impedimento para a consolidação de programas de promoção de saúde na América Latina (FERRAZ, 1999) e o Brasil não foge à regra.. Para que ações bem sucedidas não fiquem na informalidade e sofram com as mudanças políticas. é necessário que sejam oficialmente incorporadas aos serviços. Essa experiência do Distrito Federal demanda poucos recursos financeiros e poderá ser sugerida ao setor saúde como atividade de promoção de saúde, ao setor da previdência e assistência social como uma ação de promoção social para diversas faixas etárias. Poderá servir aos setores da Educação e da Cultura como forma de introdução do tema "envelhecimento populacional" nas escolas, conforme determina a Política Nacional do Idoso (BRASIL, 1986).

\section{Conclusão}

O estudo sugere que preconceitos e estereótipos existem dos dois lados. Esse fato pode prejudicar convívio social e influenciar negativamente a elaboração de leis, a formulação de políticas públicas e a atuação de profissionais que lidam com idosos e com jovens. Os estereótipos, mesmo quando positivos, são prejudiciais, uma vez que não prevêem a diversidade dos indivíduos e dá um tratamento ao grupo como se todos fossem iguais.
Os achados da presente avaliação, no entanto, parecem indicar que atividades dirigidas de integração entre gerações podem promover mudanças positivas de atitudes, favorecendo uma relação saudável entre diferentes gerações. Eles sugerem também que o contato dos jovens com os idosos poderá traduzir-se numa possibilidade de resgate dos significados atribuídos às relações interpessoais, bem como promover a inserção dos elementos da tradição que dão sentido à família e à sociedade. No entanto, esta pesquisa constitui um dos primeiros passos nessa área de investigação no Brasil e apresenta algumas limitações, incluindo a utilização de algumas perguntas que podem ter influenciado as respostas dos participantes e a falta de dados relativos à opinião dos participantes antes da intervenção. Estudos adicionais necessitam ser conduzidos para comprovação dos achados. Uma pesquisa quantiqualitativa, que combina um estudo randomizado na comunidade, observação de processo de intervenção e grupos focais, está sendo desenvolvida para a avaliação de atividades intergeracionais como programa de doutorado em promoção da saúde.

\section{Agradecimentos}

Agradecemos à Embaixada Britânica no Brasil pelo apoio financeiro à implantação do Projeto. A OPAS-DF e à FUNSAÚDE-DF pelo apoio financeiro ao desenvolvimento da pesquisa de avaliação das atividades. À direção da Escola Classe 15 de Ceilândia, Professora Maria do Socorro Belarmino, às professoras Bacy Gonçalves Dias, Simone de Moura e Maria Aparecida Diaz de Araujo, aos alunos e idosos que participaram das atividades, tornando possível esse estudo.

\section{Referencias}

BAUM, F. E. et al. Epidemiology of participation: an Australian community study. Journal of Epidemiology and Community Health, London, v.54, n.6, p.414-23, 2000. 
BORNAT, J. Reminiscence reviewed: perspectives, evaluations, achievements. Buckingham: Open University Press, 1994.

Brasil. Decreto n. 1.948, de 3 de julho. Regulamenta a Lei 8.842.de 4 de janeiro de 1994, que dispõe sobre a Política Nacional do Idoso, e da outras providências. Diário Oficial [da República Federativa do Brasil], Brasília, 4 jul.1996. Seção 1, pt. 1, p.277-79.

BRUBAKER, M. A ; POWERS, E. A. The stereotype of "old": a review and alternative approach. Journal of Gerontology, Washingtonm, v.31, n.4, p.441-447, 1976.

COLEMAN, P. G. Ageing and reminiscence process: social and clinical implications. Chichester: John Wiley, 1986.

FERRAZ, S. T. Cidades saudáveis: uma urbanidade para 2000. Brasília: Paralelo 15, 1999.

GIBSON, F. Reminiscence and recall: a guide to good practice. London: Age Concern Books, 1998.

HENKIN, E. T. Intergenerational Programming: a vehice for promoting intra-and cross-cultural understanding. Jornal Gerontological Social Work, Haworth, v.28, n.3, p.197-209, 1997.

HICKS, D. A. et al. "Attitudes" toward the elderly: a comparison of measures. Experimental Aging Research, London, v.2, n.2, p.119-124, 1976.

HIRSHORN, B. A.; PIERING, P. Older people at risk: issues and intergenerational responses. Generations, v.22, n.4, p.49-53, 1999.

KAWACHI, I. Social capital and community effects on population and individual health. Socioeconomic Status and Health in Industrial Nations, New York, v.896, p.120130, 1999.

KERRIGAN, J.; STEVENSON, N. C. Behavioural study of youth and elders in an intergenerational horticultural program. Activities, Adaptation and Aging, New York, v.22, n.3, p.142-143, 1997.

KUEHNE, V. S.; COLLIN, C. L. Observational research in intergenerational programming: need and opportunity. Journal of Gerontological Social Work, Haworth, v.28, n.3, p.183-193, 1997.
NERI, A. L. Envelhecer num país de jovens: significados de velho e velhice segundo brasileiros não idosos. Campinas: Ed. Unicamp, 1991.

NEWMAN, S. et al. Children's view on ageing: Their attitudes and values. The Gerontologist, Washington, v.37 n.3 p. 412-417, 1997.

ROBINSON, J. Empowerment \& reminiscence: possible tool in dietary health promotion in the elderly. Journal of Nutrition, Health \& Aging, Paris, v.13, p.249-260, 2000.

SEYMOUR, M. Putting an end to ageism. Canadian Nurse, Otawa, v.90, n.10, p.49-50, 1994.

SOUZA, E. M. Intergenerational interaction in health promotion: a qualitative study in Brazil. Revista de Saúde Pública, São Paulo, v.37, n.4, 2003. (No prelo)

SOUZA, E. M. Reminiscências na promoção da saúde de jovens e idosos: uma experiência bem sucedida no Distrito Federal, Brasil. Revista de Saúde do Distrito Federal, Brasília, v.12, n.1-2, p.35-37, 2001.

SOUZA, E. M. Reminiscências integrando gerações: a arte de compartilhar memórias Rio de Janeiro: Vozes, 1999.

SOUZA, E. M. A new lease of life: world health: The World Health Magazine, Geneve, n.4, p.26, 1997.

STANSFELD, S. A. Social support and social cohesion. In: MARMOT, M.;WILKINSON, R. G. Social determinants of health. Oxford: University Press, 1999.

STONES, M. J; STONES, L. Ageism: the quite epidemic. Canadian Nursing Home, White Rock, v.9, n.1, p.22-24, 1998.

TUKMAN, J.; LORGE I. Attitudes toward older workers. Journal of Applied Psychology, Arlington, v.36, n.3,p. 149$153,1952$.

TUKMAN, J.; LORGE I. Attitudes toward old people. The Journal of Social Psychology, v.37, p.249-260, 1953.

WARD, C. R. Intergenerational program evaluation for 1990s and beyond. Journal of Gerontological Social Work, Haworth, v.28, n.3, p.173-181, 1997.

WILKINSON R. G. Unhealthy societies: the afflictions of inequality. London: Routledge, 1996.

WORLD HEALTH ORGANISATION. The Ottawa Charter. Ottawa, 1986. 